\title{
Incorporating Disparity Reduction into Pay-for-Performance
}

\author{
Alyna T. Chien, $M D, M S^{\top}$ and Marshall H. Chin, MD, $M P H^{2,3,4}$ \\ 'Division of General Pediatrics, Children's Hospital Boston, Boston, MA, USA; ${ }^{2}$ Section of General Internal Medicine, University of Chicago, \\ Chicago, IL, USA; ${ }^{3}$ Diabetes Research and Training Center, The University of Chicago, IL, Chicago, USA; ${ }^{4}$ Robert Wood Johnson Foundation \\ Finding Answers: Disparities Research for Change National Program Office, The University of Chicago, Chicago, IL, USA.
}

J Gen Intern Med 24(1):135-6

DOI: $10.1007 / \mathrm{s} 11606-008-0884-6$

(C) Society of General Internal Medicine 2008

$\mathrm{O}$ ne of the concerns surrounding pay-for-performance (P4P) strategies is their potentially negative impact on racial/ethnic disparities in healthcare. We have previously described that leaders of $\mathrm{P} 4 \mathrm{P}$ programs in the United States acknowledge that their $\mathrm{P} 4 \mathrm{P}$ programs are being designed without much attention to these disparities and may contain features that may promote inequities rather than eliminate them. ${ }^{1}$

Thus far, the evidence regarding P4P's impact on disparities is limited and there is as much reason to worry as there is to be reassured. On the one hand, one study shows that physicians who are highly ranked by a combination of quality and efficiency measures in a tiered network are generally as likely to care for racial/ethnic minorities as lower ranked ones. ${ }^{2}$ On the other hand, another study suggests hospitals that disproportionately care for racial/ethnic minorities may be less able to earn bonus payments in Medicare's hospital P4P program than those who do not. ${ }^{3}$ In this issue, Millett examines this problem in the United Kingdom and still finds that P4P's impact on disparities can be ambiguous; P4P significantly reduced disparities in only two of the 20 white-minority quality indicator comparisons that were examined, while disparities increased in three of the comparisons. ${ }^{4}$

In order to successfully incorporate disparity reduction goals into existing $\mathrm{P} 4 \mathrm{P}$ programs, payors and policymakers will need to be cognizant of whether they are: (1) addressing disparities that result from differential treatment within a single institution, or from minorities disproportionately receiving care from lower quality providers; (2) using performance measures that are likely to generate the greatest yield when it comes to reducing disparities; (3) employing algorithms that reward providers for improving care while pursuing absolute benchmarks; and (4) preparing for ways in which disparity reduction and/or elimination can be tied to payment.

1. P4P strategies should take into account whether existing disparities are driven by differential treat-

I. Dr. Chien is supported by a Career Development Award from the Agency for Healthcare Research and Quality (K08 HS17146-01).

II. Dr. Chin is supported by a Midcareer Investigator Award in PatientOriented Research (K24 DK071933) and a Diabetes Research and Training Center (P60 DK20595) from the National Institute of Diabetes and Digestive and Kidney Diseases.

Published online December 17, 2008 ment of minority patients by healthcare providers within the same institution, or by minority patients tending to be cared for by lower quality providers. In the scenario where the racial/ethnic gap exists because the same providers treat minority patients differently from white ones ${ }^{5-7}$, P4P payments can be tied to providers who demonstrate that they provide both high quality and equitable healthcare. In the situation where the racial/ ethnic gap appears to exist because minorities are disproportionately cared for by lower quality providers ${ }^{5,6,8,9}$, it may be necessary to design $\mathrm{P} 4 \mathrm{P}$ programs to encourage high quality providers to care for more minorities and/or to provide lower quality providers with additional incentives to pursue quality improvement efforts. Sometimes institutions that disproportionately serve minority patients are overwhelmed with the demand for their services, are underresourced, and lack access to specialty referral.

2. P4P strategies should employ performance measures that target disparity reduction. $\mathrm{P} 4 \mathrm{P}$ program designers can target disparities in three main ways. First, they can emphasize condition-specific processes and outcomes known to have large disparities. Second, they can target more general aspects of care that have been shown to be important to minorities. Third, they can specifically reward improvements in care for minority populations and/ or the narrowing of disparities.

One example of using $\mathrm{P} 4 \mathrm{P}$ to target condition-specific treatment gaps comes from breast cancer screening and treatment. Over the past several years, the black-white disparity in screening rates has narrowed in many regions of the United States, but gaps pertaining to getting African-American women into treatment at earlier stages of breast cancer and using radiation therapy adjunctively in treatment plans still exist. ${ }^{10}$ If $\mathrm{P} 4 \mathrm{P}$ programs are aware of this racial/ethnic difference in the transition from screening to treatment, they could potentially incentivize timely referral and appropriate case management for patients with positive screening results.

An example of using P4P to target more general aspects of healthcare comes from what is known about the importance of participatory decision-making communication styles for engaging minorities across a variety of health conditions. ${ }^{11}$ If $\mathrm{P} 4 \mathrm{P}$ programs recognize the importance of these types of interactions, then they could move beyond measures of patient satisfaction and towards including measures that reflect the effectiveness of physician-patient interactions.

Lastly, P4P programs can reward providers for improving the quality of care provided to minorities specifically 
(e.g. HbAlc testing rate in African Americans with diabetes), or for demonstrating that there is no difference in the care provided across their patient population (e.g. showing that the HbAlc testing rate in African Americans is equivalent to the rate in whites).

3. P4P programs should reward performance improvement in addition to achievement. In addition to being careful about which performance measures should be targeted, $\mathrm{P} 4 \mathrm{P}$ programs should pay attention to how rewards and/or sanctions are triggered. Leaders of $\mathrm{P} 4 \mathrm{P}$ programs already appear to believe that programs that only reward providers for reaching highly set expectations or absolute benchmarks (e.g. $>90 \%$ of appropriate patients screened for colon cancer) are more likely to yield negative consequences for disparities than those that reward based on improvements in care (e.g. rising from $25 \%$ screening rates to $75 \%$ ). ${ }^{1}$ Given the equivocal evidence regarding the impact of $\mathrm{P} 4 \mathrm{P}$ on disparities, and cautions from those with experience designing and implementing these programs, P4P programs should reward providers not only for whether they reach a target, but also for how much they improve.

4. Payors and health care organizations should prepare for P4P incentives being tied to disparity reduction by stratifying quality of care data by racial/ethnic groups, comparing how they are performing for their different racial/ethnic groups, and sharing these data for internal quality improvement purposes. Policymakers are likely to begin incentivizing disparity reduction; this year Massachusetts passed legislation that partly ties Medicaid's fees to the reduction of racial/ethnic disparities. ${ }^{12}$ To start preparing for this requirement, $\mathrm{P} 4 \mathrm{P}$ programs should stratify their quality and/or cost-efficiency data by race/ethnicity to discern if and when disparities are occurring. Subsequently, health care organizations can implement institutional and/or regional remedies to reduce disparities. This gradual approach to tying $\mathrm{P} 4 \mathrm{P}$ to disparities reduction would also allow program designers and researchers to understand the methodological challenges associated with this enterprise and contemplate strategies to implement $\mathrm{P} 4 \mathrm{P}$ in a fair manner. Some of these strategies may require structural investments, like better health information technologies, but others relate to statistical conventions for dealing with performance measurement methodologies and inherent difficulties of small sample sizes (e.g. methods for aggregating across time, Bayesian versus frequentist methods of estimation). ${ }^{13,14}$

In summary, although initial P4P efforts were not designed with disparity reduction in mind, future ones can be. We have a rich enough understanding of the nature of disparities, of what is missing and effective for minority populations, and of what is important in $\mathrm{P} 4 \mathrm{P}$ design to start incorporating equity strategies into every $\mathrm{P} 4 \mathrm{P}$ initiative.

Corresponding Author: Alyna T. Chien, MD, MS, Division of General Pediatrics, Children's Hospital Boston, 300 Longwood Avenue, Boston, MA 02115, USA (e-mail: alyna.chien@childrens. harvard.edu).

\section{REFERENCES}

1. Chien AT, Chin MH, Davis AM, Casalino LP. Pay-for-performance, public reporting and racial disparities in health care: how are programs being designed. Med Care Res Rev. 2007;64:285S-304S.

2. Brennan TA, Spettell CM, Fernandes J, Downey RL, Carrara LM. Do managed care plans' tiered networks lead to inequities in care for minority patients. Health Aff (Millwood). 2008;27:1160-6.

3. Werner RM, Goldman LE, Dudley RA. Comparison of change in quality of care between safety-net and non-safety-net hospitals. JAMA. 2008;299:2180-7.

4. Millett C, Gray J, Wall M, Majeed A. Ethnic disparities in coronary heart disease management and pay for performance in the UK. J Gen Intern Med. 2009;xxx:xx-xxx.

5. Hasnain-Wynia RP, Baker DW, Nerenz DP, et al.. Disparities in health care are driven by where minority patients seek care: examination of the Hospital Quality Alliance Measures. Arch Intern Med. 2007;167:1233-9.

6. Heisler M, Smith DM, Hayward RA, Krein SL, Kerr EA. Racial disparities in diabetes care processes, outcomes, and treatment intensity. Med Care. 2003;41:1221-32.

7. Sequist TD, Fitzmaurice GM, Marshall R, Shaykevich S, Safran DG, Ayanian JZ. Physician performance and racial disparities in diabetes mellitus care. Arch Intern Med. 2008;168:1145-51.

8. Jha AK, Orav EJ, Li Z, Epstein AM. Concentration and quality of hospitals that care for elderly black patients. Arch Intern Med. 2007; 167:1177-82.

9. Bach PB, Pham HH, Schrag D, Tate RC, Hargraves JL. Primary care physicians who treat blacks and whites. [see comment]. N Engl J Med. 2004;351:575-84.

10. Masi CM, Blackman DJ, Peek ME. Interventions to enhance breast cancer screening, diagnosis, and treatment among racial and ethnic minority women. Med Care Res Rev. 2007;64:195S-242S

11. Heisler M, Bouknight RR, Hayward RA, Smith DM, Kerr EA. The relative importance of physician communication, participatory decision making, and patient understanding in diabetes self-management. J Gen Intern Med. 2002;17:243-52.

12. Commonwealth of Massachusetts Acts of 2006, Section 25, Chapter 58 "An Act Providing Access to Affordable, Quality, Accountable Health Care," Available at: http://www.mass.gov/legis/laws/seslaw06/ sl060058.htm. Accessed 3 November 2008.

13. Normand, ST, Shahian DM. Statistical and clinical aspects of hospital outcomes profiling. Stat Sci. 2007;22(2):206-26.

14. Ohlssen, DI, Sharples LD, Spiegelhalter DJ. Flexible random-effects models using Bayesian semi-parametric models: Applications to institutional comparisons. StatisMed. 2007;26(9):2088-112, Apr 30. 